\title{
ECONOMIA POPULAR SOLIDÁRIA: AÇÕES EXTENSIONISTAS NO EXTREMO SUL DO BRASIL
}

\author{
POPULAR SOLIDARITY ECONOMY: EXTENSIONIST \\ ACTIONS IN THE SOUTHERNMOST REGION OF BRAZIL
}

\author{
Simone Silva Alves* \\ Vitor Garcia Stoll ${ }^{* *}$ \\ Ticiane da Rosa Osório*** \\ Quelen Colman Espíndola Lima***
}

\section{RESUMO:}

A Economia Popular Solidária (EPS) é entendida como uma proposta econômica-política que tenciona recuperar o sentido social e ético da economia, almejando o enfrentamento das desigualdades, pobreza e exclusão social. Nesse sentido, percebeu-se a necessidade da construção de um projeto cujo cunho social permitisse compreender a realidade dos grupos de economia popular solidária. Diante disso, este texto objetiva relatar as experiências das ações desenvolvidas em dois projetos de extensão, que envolveram duas cidades da Fronteira Sul do Rio Grande Sul, vinculados à Universidade Federal do Pampa, nos Campus de Dom Pedrito e Jaguarão/RS. Neste contexto, esses projetos de extensão visavam analisar e mapear os grupos que compõem a EPS no Extremo Sul do Brasil. Este estudo, de cunho qualitativo, revelou quatro conceitos essenciais: Educação, Saberes Culturais, Gênero e Produção. Identificou-se que a cadeia de produção é distinta, composta principalmente por produtos alimentícios e artesanato, sendo que esses grupos são constituídos predominantemente por mulheres veteranas, que perpassam os saberes ao longo das gerações. Os resultados obtidos também indicam que, apesar de nem todos os sujeitos conhecerem a EPS, utilizam os pilares dessa prática econômica nas ações cotidianas.

Palavras-chave: Educação; Gênero; Produção; Saberes culturais.

\begin{abstract}
:
The Popular Solidarity Economy (EPS) is understood as an economic-political proposal that intends to recover the social and ethical sense of the economy, aiming at confronting inequalities, poverty and social exclusion. In this sense, we realized the need to build a project whose social character allowed us to understand the reality of the popular solidarity economy groups. This paper aims to report on the experiences of two extension projects, involving two cities on the South border of Rio Grande Sul, linked to the Federal University of Pampa, Campus Dom Pedrito and Jaguarão / RS. In such context, these extension projects aimed at analyzing and mapping the groups that develop EPS in the extreme South of Brazil. This qualitative study revealed four essential concepts: Education, Cultural Knowledge, Gender and Production. The production chain was seen to be distinct, mainly comprising food products and handicrafts and that these groups are predominantly constituted by middle-aged women, who pass on their knowledge through generations. The results also indicated that although not all subjects know EPS, they use the pillars of this economic practice in their everyday actions.
\end{abstract}

Keywords: Education; Gender; Production; Cultural knowledge. 


\section{Introdução}

A Economia Popular Solidária (EPS) é compreendida como um modo de organização da economia social que perpassa as questões econômicas e o lucro, pois estimula nos indivíduos à reflexividade e à criticidade referentes a diversas questões políticas, econômicas, sociais e culturais desenvolvidas no modelo de acumulação capitalista (SINGER, 2002).

Neste contexto, a EPS funciona como uma corrente de pensamento e de ação que visa à recuperação do sentido social e ético da economia para enfrentar a desigualdade, a pobreza e a exclusão social. Sua constituição é formada por grupos e associações que buscam formas de produzir e consumir, as quais estão interligadas às práticas de solidariedade, cooperação, mutualismo e autogestão (SINGER, 2004; ZARETO, 1993).

Conforme Singer (2002, p. 10), a economia solidária é outra forma de organização econômica e social, cujos princípios básicos são "a propriedade coletiva ou associada do capital, e o direito à liberdade individual". No Brasil, a partir da década de 1980, iniciam-se outras discussões teóricas sobre essas práticas econômicas alternativas, provocadas pela ampla crise do trabalho que assolou o país nesses anos. Momento especial, a criação do projeto de lei, no governo Lula, que instituiu a Secretaria Nacional de Economia Solidária (SENAES), inserida no Ministério do Trabalho e Emprego (MTE), aprovado pelo Congresso Nacional em junho de 2003. Nesse período, a lógica de compreensão do Ministério do Trabalho era de que:

Economia Solidária é um jeito diferente de produzir vender, comprar e trocar o que é preciso para viver. Enquanto na economia convencional existe a separação entre os donos do negócio e os empregados, na economia solidária os próprios trabalhadores também são donos. São eles quem tomam as decisões de como tocar o negócio, dividir o trabalho e repartir os resultados (MTE, 2015).

Com essa forma de fazer economia, o trabalhador tem a oportunidade de emancipar-se e evoluir socioeconômica e culturalmente, através da autogestão da sua produtividade, sendo que a prática da EPS implica em fatores como: ampliação das relações interpessoais, autonomia, coletivismo, solidariedade entre outros, que contribuem relevantemente para uma positiva transformação social (SINGER, 2004; ALVES, 2014).

No estado do Rio Grande do Sul, as primeiras experiências de cooperação econômica, assim como noutras realidades estaduais do Brasil, se desenvolveram entre as décadas de 1980, aumentando quantitativa e qualitativamente a partir dos anos 1990. Nessa época, as práticas de solidariedade econômica estavam vinculadas a comunidades de imigrantes europeus, especialmente alemães e italianos (ROSA, 2013). Atualmente, a EPS tem ganhado espaço em diversos setores e áreas do referido Estado.

Neste sentido, considerando a relevância em conhecer e compreender melhor o cenário da EPS, foram elaborados os seguintes projetos extensionistas: "Os Saberes das Redes de Colaboração Solidária da fronteira do extremo sul do Brasil" e "Economia Solidária: Fomentando a Geração de Saberes, Trabalho e Renda na Contemporaneidade", vinculados à
Universidade Federal do Pampa - UNIPAMPA, inicialmente desenvolvidos no município de Dom Pedrito/RS e posteriormente em Jaguarão/RS.

Localizado na região da Campanha Gaúcha, o município de Dom Pedrito possui cerca de 40 mil habitantes, ocupando uma extensão territorial de $5.192 \mathrm{~km}^{2}$, com alto índice de urbanização $(90,6 \%)$ e baixa densidade demográfica (7,69 hab. / km2) (IBGE, 2010). De acordo com Alves e colaboradores (2015, p. 1), a cidade tem "predominância histórica da atividade pecuária extensiva e o cultivo de arroz, e mais recentemente, a expansão da soja em larga escala". No entanto, os sujeitos que participam da Feira Municipal, desenvolvida nas sextas-feiras na praça principal, e que compõem a EPS nesta cidade, são os microempreendedores da agricultura familiar, excluídos do agronegócio por não produzirem em grande escala.

Já o município de Jaguarão localiza-se no Extremo Sul do Brasil, fazendo fronteira com a cidade de Rio Branco, no Uruguai. Possui extensão territorial de $2.051 \mathrm{~km}^{2}$, cerca de 28 mil habitantes, sendo $93,46 \%$ residentes na área urbana (IBGE, 2010). Estudos de Stoll e colaboradores $(2017$, p. 2) sugerem que, por se localizar em uma região fronteiriça, "há um fluxo grande de pessoas, bens e serviços entre os dois municípios, o que favorece a criação de espaços econômicos solidários, através da produção e comercialização de artesanato, produtos alimentícios, de higiene, dentre outros". Apesar disso, Jaguarão enfrenta inúmeras dificuldades econômicas, sociais e educacionais. Tal realidade faz com que alguns cidadãos, por motivos ainda não aferidos, não estejam inseridos no mercado de trabalho e/ou necessitem complementar a renda mensal de sua família. Por isso, recorrem às atividades de autogestão.

Com base nesses pressupostos, considera-se de suma importância a construção de propostas educativas que primem pelos valores da EPS, as quais proporcionem o diálogo e a reflexão sobre as diversas formas de (re)pensar o fazer econômico. Acredita-se que as relações estabelecidas entre educação, trabalho e economia proporcionam o pensar e o atuar de um sujeito além do meio onde vive, permitindo a valorização e o resgate das experiências históricas, bem como o entendimento de que o trabalho coletivo pode colaborar na construção da identidade social e coletiva, por meio de elementos e materiais simbólicos.

Dessa forma, partindo do entendimento de que o processo educativo não acontece desassociado da construção da cidade, da cultura, das identidades, do trabalho, dos tempos e espaço de socialização, o recorte apresentado neste artigo objetiva analisar e mapear os grupos que compõem a EPS nas cidades de Dom Pedrito e Jaguarão/RS

$\mathrm{O}$ artigo estrutura-se em quatro seções: a primeira apresenta o relato das experiências das ações desenvolvidas em dois projetos de extensão, os quais envolvem duas cidades da Fronteira Sul do Rio Grande Sul, vinculados à Universidade Federal do Pampa, nos Campus de Dom Pedrito e Jaguarão/RS; na segunda, traz os caminhos metodológicos traçados nos projetos; na terceira, os resultados obtidos nos projetos de extensão e os conceitos que emergiram; e, por fim, sinalizam-se algumas considerações parciais. 


\section{Algumas ações de extensão na Fronteira Sul}

Atualmente, vive-se numa situação socioeconômica complexa, especialmente quanto ao aumento do nível da desigualdade econômica da população mundial. Nos últimos anos, o volume de riquezas de $1 \%$ da população mundial equivalem aos outros 99\%. É o que indica a ONG Britânica Internacional (OXFAM, 2015). Segundo a pesquisa, em 2009, o $1 \%$ mais rico do planeta concentrava $44 \%$ dos recursos mundiais. Em 2014, esta razão subiu para 48\% (OXFAM, 2015). Destarte, torna-se relevante pesquisar as redes de colaboração solidária da Fronteira do Extremo Sul do Brasil, pois esses espaços são marcados por inúmeras dificuldades e muitas vezes esquecidos por seus respectivos governos nacionais.

Essa faixa de fronteira apresenta um índice populacional maior que as demais áreas de fronteiras do restante do Brasil. Porém, as características econômicas são comuns, como a insuficiência de infraestrutura de transportes e a ausência de uma gestão compartilhada do território fronteiriço que muitas vezes comprometem o crescimento da economia destas regiões. Por essas razões, as populações das áreas de fronteira costumam criar estratégias de sobrevivência, independentemente das decisões advindas das capitais nacionais, aproveitando os fluxos (de pessoas, bens e serviços).

Por fim, a proposta do projeto é baseada também no fato que, desde 2011, são ofertadas vagas especiais para o ingresso de estudantes uruguaios, fato que tem favorecido o intercâmbio entre Brasil e Uruguai, fortalecendo os laços através das ricas trocas culturais e de saberes entre fronteiriços e discentes de todo o Brasil que ingressam na universidade, tornando possível uma substancial ampliação dos horizontes que norteiam o convívio da comunidade acadêmica.

Uma das missões da Universidade Federal do Pampa é a promoção de uma educação superior qualificada e, a partir disso, formar cidadãos capacitados e empenhados com o desenvolvimento regional, nacional e internacional. Este perfil vislumbrado é formado por meio do compromisso no qual a Instituição está ancorada, em princípios como a ética, o respeito e a solidariedade. Assim sendo, para que todos os objetivos e princípios sejam alcançados, é de extrema relevância que a prática pedagógica "conceba a construção do conhecimento como o resultado interativo da mobilização de diferentes saberes, que não se esgotam nos espaços e tempos delimitados pela sala de aula convencional" (UNIPAMPA, 2017, p. 16).

De acordo com a Política Nacional de Extensão Universitária (FORPROEX, 2012), um dos grandes desafios que se tem nas instituições de Ensino Superior é o de:

Exercitar o papel transformador da Extensão na relação da Universidade Pública com todos os outros setores da sociedade, no sentido da mudança social, de superação das desigualdades, eliminando, nesse exercício, ações meramente reprodutoras do status quo. (FORPROEX, 2012, p. 23)

A prática em questão é fundamental, já que por meio dela pode-se articular o ensino, pesquisa e extensão na formação acadêmica dos sujeitos e, dessa forma, desafiá-los ao entendimento da realidade e do contexto no qual estão envolvidos, no sentido de que sejam capazes de buscar diferentes possibilidades de transformação.

Com base nesses pressupostos e reconhecendo a relevância da extensão universitária na formação pessoal, profissional e social da comunidade, acadêmicos, técnicos e professores, a seguir, são apresentados os projetos de extensão que entrelaçam o artigo. Compreende-se que esses projetos possibilitam o compartilhamento dos saberes científicos advindos da universidade com os saberes populares da comunidade, de modo que a interação entre os saberes transforme a realidade social.

Diante de tal demanda, em 2016, docentes, discentes, técnicos e algumas pessoas que participam da Feira Municipal de Dom Pedrito/RS, da Feira, da Casa e do Fórum de Economia Solidária da cidade de Jaguarão/RS, mobilizaram-se para criar um projeto de extensão. O primeiro projeto, "Os Saberes das Redes de Colaboração do Extremo Sul do Brasil", buscou mapear os Empreendimentos Econômicos Solidários (EES) que compõem as Redes de Colaboração Solidária da Fronteira do Extremo Sul do Brasil, nas cidades supracitadas.

Entende-se por "rede" a teia de organização social que permite aos indivíduos a criticidade diante de diversas questões como: as políticas, as econômicas e as sociais. As redes funcionam como potencializadoras das conexões existentes e na união de empreendimentos solidários nos ramos de produção, comercialização, financiamento e outras organizações populares (FRANÇA FILHO; LAVILLE, 2004; SINGER, 2002).

O segundo projeto, "Economia Solidária: Fomentando a Geração de Saberes, Trabalho e Renda na Contemporaneidade", investiga os processos de origem, constituição, mobilização, organização e ação dos movimentos da EPS e dos EES que corroborem como possibilidade de outra forma de organização econômica e social na cidade de Jaguarão/RS. Além disso, tenciona a criação de uma base de dados sobre os grupos da EPS, direcionada à comunidade acadêmica, aos gestores públicos e gestores dos empreendimentos solidários, com $\mathrm{o}$ intuito $\mathrm{de}$ fortalecer as Redes da EPS.

Ressalta-se que essas ações extensionistas também visaram a interação entre docentes, discentes e comunidade, estimulando mediações, criticidade e a criação de tecnologias para emancipação das coletividades.

\section{Metodologia}

Compreende-se que a Extensão Universitária é o processo educativo, cultural e científico que articula o Ensino e a Pesquisa de forma indissociável e viabiliza a relação transformadora entre Universidade e Sociedade. Desse modo, as universidades tornam-se laboratórios em que a pesquisa e a extensão se interligam nas experiências de apoio aos empreendimentos econômicos solidários, que além de resultar em melhoria no desempenho dos elementos de produção material e cultural, geram monografias, dissertações, teses e pesquisa em geral. 
Sabe-se que os estudos relacionados à economia solidária ainda são pouco pesquisados, contudo, entende-se que a crescente consolidação da extensão universitária frente à situação econômica da população de baixa renda tem apoiado os grupos solidários por meio da assistência técnica, formação para a gestão e profissionalização.

Este texto trata-se de um estudo qualitativo, de caráter descritivo (GIL, 2008). Estudos qualitativos respondem a questões muito particulares, "se preocupam, nas ciências sociais, com o nível de realidade que não pode ser quantificado. Ou seja, trabalham com o universo de significados, motivos, aspirações, crenças, valores e atitudes [...]" (MINAYO, 2001, p. 21).

O presente estudo tem como objetivo relatar as ações dos Projetos de Extensão: "Os Saberes das Redes de Colaboração do Extremo Sul do Brasil" e "Economia Solidária: Fomentando a Geração de Saberes, Trabalho e Renda na Contemporaneidade", explicitando suas metas, organização do trabalho, além de fazer uma breve análise do desenvolvimento dos projetos. Destaca-se que compuseram a equipe executora dos projetos de extensão os autores deste texto e os colaboradores, incluindo docentes, discentes, técnicos e comunidade externa.

Os discentes que participaram dos projetos de extensão são de distintos cursos da graduação e pósgraduação da UNIPAMPA, tais como: Licenciatura em Ciências da Natureza, Bacharelado em Enologia, Tecnólogo em Agronegócio, Licenciatura em Pedagogia, Licenciatura em História, Tecnólogo em Gestão de Turismo e Mestrado em Ensino. Ressalta-se que o desenvolvimento das ações extensionistas proporcionaram aos discentes integrar os processos de ensino-aprendizagem por meio de uma prática interdisciplinar dentro dos processos sociais, pois a participação nas ações de extensão proporcionou outros elementos culturais para a construção de novos conhecimentos, vivências e saberes sociais.

Dessa forma, a extensão universitária tem a responsabilidade de, por um lado, promover a formação integral do acadêmico, permitindo-lhe a experimentação e a prática profissional orientada, mas, ao mesmo tempo, o desenvolvimento de sua responsabilidade cidadã.

A organização metodológica dos projetos foi desenvolvida da seguinte forma: as informações foram coletadas através de observações, rodas de conversas, questionários e entrevistas realizadas com os empreendedores sociais da Feira Municipal de Dom Pedrito/RS, Feira, Casa e Fórum de Economia Popular Solidária de Jaguarão/RS. Essas informações foram sintetizadas na Figura 1.

Figura 1 - Síntese das etapas desenvolvidas nos projetos de extensão.

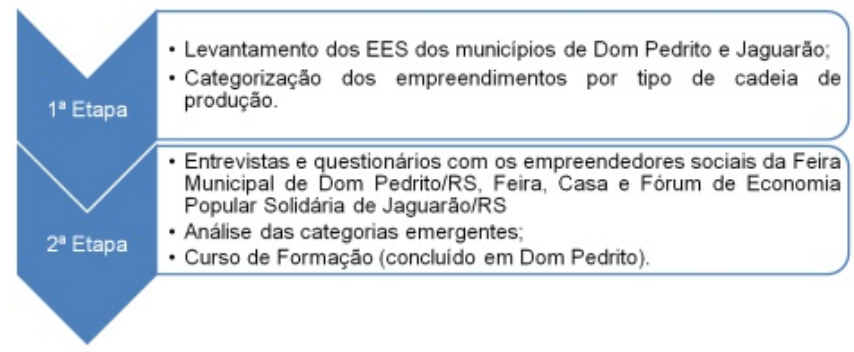

Fonte: Autores (2019)
A técnica de análise visou expor o relato das ações extensionistas e foi estruturada em três etapas distintas: pré-análise, exploração do material e tratamento dos resultados (BARDIN, 2011). Inicialmente, realizou-se a leitura de todo o material coletado: entrevistas, relatórios de observação e questionários. $\mathrm{Na}$ sequência, transcreveram-se essas informações, a partir das quais emergiram conceitos que se revelaram partes essencias que compõem os grupos de economia popular solidária dos projetos de extensão.

Os conceitos são: Gênero, que apresenta a faixa etária e o gênero dos sujeitos, onde se destaca a participação majoritária de mulheres veteranas na EPS; Educação, que descreve o nível de escolaridade, bem como o desejo ou não de continuidade dos estudos; Saberes Culturais, que evidenciam traços das perspectivas dos feirantes e empreendedores em relação aos pilares da EPS; e a Produção, onde é delineada a cadeia produtiva dos grupos da EPS e os desafios em comum entre as cidades. Por fim, os resultados foram submetidos ao tratamento das informações, sendo realizada a inferência e a interpretação dos resultados.

\section{Relato de experiências e Discussão}

$\mathrm{Na}$ análise dos resultados do Conceito Gênero, mapeou-se que, no município de Dom Pedrito/RS, a Feira é constituída por 35 feirantes [28 mulheres $(80 \%)$ e sete homens (20\%)]. A mais nova possui 20 anos e a mais experiente 77 anos, sendo a média de 50 anos (STOLL et al., 2016). Em Jaguarão, constatou-se que há um total de 93 empreendedores cadastrados na Casa de Economia Solidária, com faixa etária e gênero semelhante, sendo respectivamente: 80 mulheres (86\%) e 13 homens (14\%), tendo a mais nova 25 anos e a mais experiente 82 anos, perfazendo entre todos uma média de 46 anos. Dessa forma, fica evidente a demarcação de mulheres na EPS, sobretudo as veteranas.

Ao se utilizar o termo mulheres veteranas, não se está referindo-se a mulheres idosas, mas, sim, à experiência vivenciada neste contexto, passada principalmente de geração para geração. De acordo com Alves (2014), as mulheres veteranas na EPS constroem seus saberes em decorrência de suas vivências e experiências ao longo da vida, decorridos da experiência do trabalho. Tais saberes se acumulam com o tempo, tanto é que quando se perguntou "como você aprendeu a fazer o que faz", as mulheres responderam: "eu aprendi com mãe, com a avó, com a família, com outras mulheres".

Entende-se que as mulheres que participaram dos projetos de extensão têm o trabalho como valor fundamental da vida humana. $\mathrm{O}$ trabalho feminino nos espaços da EPS correlaciona a atividade, a liberdade e a satisfação das necessidades básicas de sobrevivência, em que o fundamental é o reconhecimento individual e coletivo das pessoas, pois suas ferramentas essenciais são a solidariedade e a sororidade (ALVES, 2014). Em vista disso, a EPS pressupõe a ação coletiva que possibilita experimentar os saberes da experiência de um coletivo (mulheres), que ressignificam e configuram novas formas de trabalho. 
No Conceito Educação, no município de Dom Pedrito, constatou-se que, em relação à escolaridade, os participantes da pesquisa possuem níveis de ensino heterogêneos, pois $6 \%$ não são alfabetizados; $28 \%$ não concluíram o Ensino Fundamental; 27\% completaram o Ensino Fundamental; 13\% não concluíram o Ensino Médio; $13 \%$ possuem o Ensino Médio completo e apenas $13 \%$ dos participantes possuem o Ensino Superior (STOLL et al., 2016). No município de Jaguarão, os dados ainda estão em construção.

A partir destas informações, percebeu-se que o nível de educação formal é baixo, e que os feirantes constituem profissão através da troca de saberes no âmbito familiar, como também entre os feirantes e/ou realizando cursos de qualificação. Isso evidencia que há um elo entre a EPS e a Educação Popular, definida por Paulo Freire (1993), isto é, como "o esforço de mobilização, organização e capacitação de classes populares; capacitação técnica e científica" (FREIRE, 1993 , p. 19). Portanto, abre o espaço para as necessárias ações colaborativas da Academia nesse campo de educação, formação e capacitação

Ao se compreender a educação como um ato político, segundo a lógica freireana, entende-se que ela se realiza como construção coletiva, que reeduca todos os sujeitos envolvidos, abarca postura e atitude diante do mundo e do homem, que é diferente um do outro com suas culturas e crenças (FREIRE, 1982). Neste sentido, percebe-se a necessidade de articulação entre a EPS e as políticas de educação, especialmente a Educação de Jovens e Adultos (EJA), já que $73 \%$ dos pesquisados manifestaram o desejo de voltar a estudar.

A partir da análise da Categoria Saberes Culturais, compreende-se este conceito como o acúmulo de conhecimento produzido por várias gerações; conhecimentos construídos com sentido de pertencimento, marcado pelas formas de viver e compreender o mundo, suas representações e valores (SINGER, 2004). Logo, esta categoria evidencia traços das perspectivas dos feirantes e empreendedores em relação aos pilares da EPS, tais como: autogestão, cooperação, reciprocidade, solidariedade e bem-comum.

Ressalta-se que, no município de Dom Pedrito, a maioria dos feirantes admitiu não ter conhecimento sobre a EPS, no entanto, $86 \%$ afirmaram que partilham opiniões sobre os produtos através de conversas e trocas de saberes práticos, assim como novas ideias. Além disso, também afirmaram compreender o trabalho coletivo, pois a feira só é constituída através da colaboração individual em prol do grande grupo. Esses conceitos elencados pelos feirantes foi um dos motivadores para a criação do curso "Organização e Gestão de Empreendimentos Econômicos Solidários", do projeto de extensão "Formação de Empreendedores Sociais", que realizou palestras interativas e rodas de conversas que visaram fomentar o conceito da EPS entre os feirantes e também fortalecer o grupo desta cidade. $\mathrm{Na}$ ocasião, participaram 73 pessoas, envolvendo outros grupos, como participantes do CRAS (Centro de Referência da Assistência Social) e da Casa de Curso de Dom Pedrito (STOLL et al., 2016).

Já em Jaguarão, verificou-se que os sujeitos se organizam através de grupos da EPS, distribuídos na Casa, Fórum e Feira do município. Constatou-se que $49 \%$ caracterizam a EPS como trabalho coletivo, $32 \%$ como comércio justo e $19 \%$ como saberes populares.
Ressalta-se que esses sujeitos primam pelos pilares básicos da EPS, pois buscam uma maneira justa de comercializar os seus produtos.

Em relação ao Conceito Produção, verificou-se que os produtos comercializados durante a feira de Dom Pedrito são unânimes ao setor alimentício, no qual os resultados apontam uma elevada produtividade no ramo da panificação, como cucas, pães, bolachas, pastéis, entre outros. No entanto, produtos como doces, queijos, sucos e vinhos, peixes, salames, linguiças e hortifrúti em geral também são comercializados com boa representatividade (STOLL et al., 2016).

Evidencia-se a diversidade de opções alimentícias ofertada à comunidade pedritense, que, segundo os feirantes, proporciona condições para o fortalecimento e continuidade da realização da feira, já que os produtores trabalham com a perspectiva da economia solidária sustentável.

Na cidade de Jaguarão, mapeou-se a existência de 98 Empreendimentos Econômicos Solidários, divididos em três grupos: (a) artesanato, (b) produtos alimentícios e de higiene, e (c) artesanato e produtos alimentícios. O primeiro corresponde a $60 \%$ do total, sendo $39 \%$ artesanato com materiais recicláveis e $21 \%$ materiais têxteis. $\mathrm{O}$ segundo representa $23 \%$ caracterizado pela produção de pães e bolos $(12 \%)$, produtos de higiene e aromatizantes (9\%), hortifruti e água ardente artesanal (2\%). E o terceiro (17\%), além do artesanato, comercializa panificação.

Apesar da variabilidade de produtos comercializados em ambas as cidades e a relevância desta com a comunidade, tanto o grupo de feirantes de Dom Pedrito, quanto os empreendedores sociais de Jaguarão enfrentam desafios semelhantes. Os feirantes de Dom Pedrito relataram que não possuem um espaço físico adequado para comercialização de seus produtos, visto que, atualmente, utilizam a praça central da cidade apenas nas sextas-feiras, no turno matutino. Em contrapartida, o grupo da EPS de Jaguarão luta para obter um espaço gratuito nas dependências do mercado público, pois até o momento não foi acordado com a gestão municipal.

\section{Considerações finais}

Acredita-se que, para alcançar uma sociedade em que todas as pessoas sejam tratadas com igualdade, é necessário que outra forma de organização econômica e social seja estabelecida, pois há que se criarem soluções para intervir na crise ambiental e societária que assola a sociedade atualmente. Considerando exemplo de outros Projetos que têm mudado a vida de trabalhadores atuantes em empreendimentos solidários, os projetos descritos neste artigo buscam resgatar os princípios da EPS, trabalhando com grupos formais e informais na formação de empreendedores sociais, para que haja uma melhoria no desenvolvimento das suas atividades.

Inicialmente, os Projetos caracterizaram esses grupos como informais, a exemplo dos feirantes de Dom Pedrito, que mesmo não conhecendo teoricamente os conceitos da EPS, nela se fundamentam para trabalhar em grupos, ao passo que, no município de Jaguarão, percebeu-se uma estrutura 
mais coesa, estruturada através do Fórum, Feira e Casa da EPS. Salienta-se que o conhecimento produzido e compartilhado pelos grupos constitui um local essencial para construção das trocas de conhecimento entre universidade e comunidade, pois os projetos de extensão apresentados visam aproximar as distantes realidades sociais e demandas de setores diversos que compõem a complexa rede de problemas em que se vive. O diálogo crítico com as problemáticas sociais pode reconectar as universidades para o desafio de um olhar interdisciplinar, cada vez mais necessário no contexto social contemporâneo (FREIRE, 1982).

Identificou-se que o gênero feminino é predominante nos espaços da EPS e que essas mulheres são veteranas, construindo seus saberes através do conhecimento perpassado ao longo das gerações. Além disso, percebeu-se que os saberes culturais podem contribuir no reconhecimento e na valorização das relações dos sujeitos consigo, com o outro e com o mundo, de modo que se reconheça o caráter inacabado do ser humano (FREIRE, 2011). Para tanto, a educação tem uma missão fundamental no processo de conscientização crítica da realidade aos sujeitos, com intuito de reorganizar outra sociabilidade.

Por fim, salienta-se que estudar o movimento e o contexto da EPS nas cidades pesquisadas, bem como as suas práticas derivadas, foi relevante para identificar as potencialidades $\mathrm{e}$ as necessidades (materiais $\mathrm{e}$ estruturais) que os agentes envolvidos têm enfrentado. A partir deste conhecimento, o desafio futuro destes grupos de extensão será planejar parcerias sociais e desenvolver ações extensionistas que comecem a tratar a Economia Popular Solidária com a sua devida esfericidade e relevância local.

\section{Referências}

ALVES, S. S. Saberes das mulheres veteranas na Economia Solidária: Sororidade a outra Educação! 2014. 173 f. Tese (Doutorado em Educação) - Programa de PósGraduação em Educação, Faculdade de Educação, Universidade Federal do Rio Grande do Sul, Porto Alegre, 2014.

ALVES, S. S.; WERKA, C.; SILVA, D.; OLALDE, A. R. Religando a produção ao consumo: a criação da feira de economia popular no Município de Dom Pedrito - RS. In: CONGRESSO LATINO-AMERICANO DE

AGROECOLOGIA, 5., 2015, La Plata, Argentina. Anais... La Plata, 2015. Disponível em:

$<$ http://sedici.unlp.edu.ar/bitstream/handle/10915/58039/Do cumento completo.pdf-

PDFA.pdf? sequence=1\&isAllowed=y>. Acesso em: $28 \mathrm{fev}$. 2019.

BARDIN, L. Análise de conteúdo. São Paulo: Edições 70, 2011.

FORPROEX. Fórum de Pró-Reitores de Extensão das Universidades Públicas Brasileiras. 2012. Disponível em: $<$ http://proex.ufsc.br/files/2016/04/Pol\%C3\%ADticaNacional-de-Extens\%C3\%A3o-Universit $\%$ C3\%A1ria-ebook.pdf $>$. Acesso em: 02 jun. 2019
FREIRE, P. Pedagogia do Oprimido. São Paulo: Paz e Terra, 1982.

FREIRE, P. Que fazer: a teoria e prática em educação popular. Petrópolis/RJ: Vozes, 1993.

FREIRE, P. Pedagogia da Autonomia: saberes necessários a prática educativa. São Paulo: Paz e Terra, 2011.

GIL, A. C. Como elaborar projetos de pesquisa. 4. ed. São Paulo: Atlas, 2002.

IBGE. Instituto Brasileiro de Geografia e Estatística. Censo 2010. Rio de Janeiro: IBGE, 2010. Disponível em: $<$ https://cidades.ibge.gov.br/brasil/rs/dom-pedrito $>$. Acesso em: 28 fev. 2019.

MINAYO, M. C. de S. Pesquisa Social: teoria, método e criatividade. 19.ed. Petrópolis: Vozes, 2001.

MTE. Ministério do Trabalho e Emprego. Economia Solidária: O que é? 2015. Disponível em:

$<$ http://trabalho.gov.br/trabalhador-economia-solidaria/oque-e>. Acesso em: 28 fev. 2019.

OXFAM. Oxford Committee for Famine Relief . Comitê de Oxford de Combate à Fome. Riqueza: tenerlo todo y querer más en manos de uma pequeña elite. Informe Temático de Oxfam. Enero de 2015. Disponível em:

$<$ https://www.oxfam.org/sites/www.oxfam.org/files/file_atta chments/ib-wealth-having-

all-wanting-more-190115-es.pdf>. Acesso em: 02 jun. 2019.

ROSA E. P. Políticas Públicas de Economia Solidária no Rio Grande do Sul. 2013. 148 f. Dissertação (Mestrado em Sociologia) - Programa de Pós-Graduação em Sociologia, Instituto de Filosofia e Ciências Humanas, Universidade Federal do Rio Grande do Sul, Porto Alegre, 2013.

SINGER, P. Introdução à Economia Solidária. São Paulo: Perseu Abramo, 2002.

SINGER, P. Um olhar diferente sobre a Economia Solidária. In: FRANÇA FILHO, G. C. de; LAVILLE, J. L. Economia Solidária: uma abordagem internacional. Porto Alegre: Editora da UFRGS, 2004. p. 6-11.

STOLL, V. G.; ALVES, S. S.; ESPINDOLA, Q. C.; VEIGA, G. L. L. Educação Popular e Economia Solidária: a Formação de empreendedores sociais em Dom Pedrito, Rio Grande do Sul. Revista Guará, v. 6, n. 5, p. 29-38, 2016.

STOLL, V. G; ALVES, S. S.; DIAS, P. H. V.; ZDRADEK, R. Economia Popular Solidária: Desafios e Possibilidades. In: SALÃO INTERNACIONAL DE ENSINO, PESQUISA E EXTENSÃO, 9., 2017, Santana do Livramento. Anais... Santana do Livramento, 2017. Disponível em: http://seer.unipampa.edu.br/index.php/siepe/article/view/311 99/16702. Acesso em:08 jan. 2019.

\section{UNIPAMPA. Projeto Pedagógico de Curso da} Licenciatura em Ciências da natureza. 2017. Disponível em:

$<$ http://dspace.unipampa.edu.br/bitstream/riu/110/1/PPC_Ci $\%$ C 3\%AAncias\%20da\%20Natureza_Dom\%20Pedrito.p $\overline{d f}>$. Acesso em: 28 fev. 2019.

ZARETO, L. Economia de Solidariedade e Organização Popular. In: GADOTTI, M.; GUTIÉRREZ, F. Educação comunitária e economia popular. São Paulo: Cortez, 1993. p. 34-58. 